\title{
Toxicities effects of pharmaceutical, olive mill and textile wastewaters before and after degradation by Pseudomonas putida $\mathrm{mt}-2$
}

\author{
Hedi Ben Mansour ${ }^{1 *}$, Afef Dellai ${ }^{1 \dagger}$ and Yosra Ayed ${ }^{2}$
}

\begin{abstract}
Background: Removal of numerous classes of chemical pollutants from the industrial wastewater such as textile, pharmaceutical and olive mill using conventional wastewater treatment, is incomplete and several studies suggested that improvement of this situation would require the application of biological treatment techniques. Dyes, polyphenols and drugs are an environmental pollutants extremely toxics to plants and other living organisms including humans. These effluents were previously treated by Pseudomonas putida. The main of this work was to evaluate the in vivo toxicity of the three wastewaters.

Methods: Writhes and convulsant effect of effluents were carried out and were compared to the treated effluents. Only pharmaceutical wastewater was exhibited a convulsant effect which observed in mice treated by effluent. On the other hand, all industrial wastewater induced significantly an algogenic effects particularly when mice were treated by the pharmaceutical wastewater (Number of writhes $=44$ ).

Conclusion: Toxicity was totally removed when mice were treated by the bio remediated effluent. This indicates that $P$. putida was able to completely detoxify the toxic industrial effluent.
\end{abstract}

Keywords: Industrial wastewater, Bioremediation, Pseudomonas putida mt-2, Algogenic effect, Convulsant effect

\section{Background}

Over the last century, continued population growth and industrialization have resulted in the degradation of various ecosystems on which human life relies on. In the case of ocean and river quality, such pollution is primarily caused by the discharge of inadequately treated industrial wastewater. Due to increasing awareness about the environment and more stringent environmental regulations, treatment of industrial wastewater has always been a key aspect of research. Much work has been done in developing and testing newer techniques and their combinations for wastewater treatment [1,2]. In Tunisia, some of the industrial sectors presenting a serious threat to the surrounding eco-system due to its usage of a vast array of organic compounds which can therefore reach

\footnotetext{
* Correspondence: hdbenmansour@gmail.com

+ Contributed equally

'Laboratoire de biotechnologie et Valorisation de Bio Géo Ressources (LBVBGR) Institut Supérieur de Biotechnologie - ISBST BioTechPole Sidi Thabet Université Manouba, Ariana 2020, Tunisie

Full list of author information is available at the end of the article
}

natural water resources are the textile, pharmaceutical and olive mill industries. The quality of these industrial effluents, thus, has substantial influence on the quality of surface water. Raw wastewaters are highly loaded with organic matter up to several grams per liter of organic carbon that may consist of well- and poorly degradable bio-genic and synthetic organic compounds (such as dyes, polyphenols, pharmaceutical drugs, antibiotic, heavy metals etc.) [3-5]. Pharmaceutical, olive mill and textile industrial effluents require treatment before delivery to municipal treatment plants or the direct discharge into surface waters. In the treatment of these wastewaters, biological treatment appears to be a promising technology compared to physicochemical treatment methods. These least, usually developed by industries, are frequently regarded as a regulatory obligation, increasing capital and running costs and yielding negative economic returns.

In previous work [3-5]P. putida, cultivated under continuous shaking incubation, is revealed able to treat

\section{C) BïoMed Central}


these industrial effluents. This result is very important because the same studies indicated that TW, PW and OMW exhibited highly in vivo and in vitro genotoxicity, lipoperoxidation and inhibit strongly cholinesterase activity.

In this study, we tested the ability of the TW, PW and OMW before and after treatment with P. putida mt-2 to induce algogenic and convulsant effects in mice.

\section{Methods}

\section{Chemicals}

Pentylenetetrazole (PTZ), acetic acid and phenobenzoquinone (PBQ) were purchased from Sigma-Aldrich (Steinheim, Germany).

\section{Wastewaters}

Toxicity assessment experiments were performed with three industrial wastewaters (i) The textile wastewater used in the present study was obtained from an textile ennoblement industry (located in Sousse: Center of Tunisia), this effluent contains five azo dyes Yellow GR $(\approx 100 \mathrm{mg} / \mathrm{l})$; Red FE3B ( $\approx 50 \mathrm{mg} / \mathrm{l})$; Blue BRR $(\approx 50 \mathrm{mg} / \mathrm{l})$; Blue GLL (75 mg/l) and Brown BL (75 mg/l); dispersant (sarabide $10 \mathrm{~g} / \mathrm{l}$ ) and two fixative agents (sodium sulphate $20 \mathrm{~g} / \mathrm{l}$ and Rewin ACP $5 \mathrm{~g} / \mathrm{l})$, finally potassium nitrate $(1 \mathrm{~g} / \mathrm{l})$, and some heavy metals ( $\mathrm{Zn}, \mathrm{Pb}, \mathrm{Cu}, \mathrm{Fe}$ ) [3] (ii) The Olive mill wastewater (OMW) was obtained from an olive oil production plant (located in Melloulech: centre of Tunisia), the OMW was derived from discontinuous process for extraction of olive oil (chemical characteristics: pH: 5.1; COD: 93 g/l; N: 1340 mg/l; P: 720 mg/l; K: 6200 mg/l; phenols: $8400 \mathrm{mg} / \mathrm{l}$; glucose: $1200 \mathrm{mg} / \mathrm{l}$ ) [4] and finally (iii) Mixture of two pharmaceutical wastewater obtained from two pharmaceutical industries located in the north and center of Tunisia. The wastewater contained a mixture of organic compounds among which were celiprol, losartan, enalapril, buflomedil, losartan and carvedilol (cardiology drug); oseltamivir (anti-viral drug); sucralose and simvastatine (nutrition metabolism drug) and finally ciprofloxacin (antibiotic drug) [5].

\section{Wastewaters bioremediation}

Biodegradation was conducted with $P$. putida mt-2 under aerobic condition. The biodegradation conditions were previously described [3-5].

\section{Animals}

Swiss mice (20-30 g) of both sexes, provided from Pasteur institute (Tunis, Tunisia) were used. Animals were fed a standard diet ad libitum and allowed free access to drinking water. Housing conditions and in vivo experiments were approved according to the guidelines established by the European Union on Animal care (CEE Council 86/609).

\section{Convulsant and writhing studies in mice}

Animals were randomly divided into nine groups:

1. Animals given a single dose $(10 \mathrm{~mL} / \mathrm{kg} \mathrm{bw})$ of culture medium run in the presence of $P$. putida mt-2 and without textile effluent as negative control group.

2. Animals given a single dose of pentylenetetrazole (PTZ) $(0.9 \mathrm{~g} / \mathrm{Kg} \mathrm{w})$ which constitute the positive control group for the convulsant test.

3. Animals given a single dose of PBQ $(0.4 \mathrm{~g} / \mathrm{Kg} \mathrm{w})$ which constitute the positive control group for the Writhing test.

4. Animals given a single dose of untreated TW, administrated intraperitoneally (ip) $(10 \mathrm{~mL} / \mathrm{kg} \mathrm{bw})$.

5. Animals given a single dose of untreated PW, administrated intraperitoneally (ip) $(10 \mathrm{~mL} / \mathrm{kg} \mathrm{bw})$.

6. Animals given a single dose of untreated OMW, administrated intraperitoneally (ip) $(10 \mathrm{~mL} / \mathrm{kg} \mathrm{bw})$.

7. Animals given a single dose of treated TW by putida mt-2, administrated intraperitoneally (ip) (10 mL/kg bw).

8. Animals given a single dose of treated PW by P. putida mt-2, administrated intraperitoneally (ip) $(10 \mathrm{~mL} / \mathrm{kg} \mathrm{bw})$.

9. Animals given a single dose of treated OMW by P. putida mt-2, administrated intraperitoneally (ip) $(10 \mathrm{~mL} / \mathrm{kg} \mathrm{bw})$.

It is of note that our results clearly showed that the selected dose of wastewaters and its biodegradation derivatives administrated alone to animals did not exhibited change of the rate of mortality, the body weight, the feed intake and the size and shape of liver and kidney.

For the convulsion study, the time taken before the onset of colonic convulsions and mortality were recorded. These parameters were compared in treated animals, by each effluent, with those of control animals (PTZ) $(0.9 \mathrm{~g} / \mathrm{Kg} \mathrm{w})$, in order to assess the convulsant effect.

For the writhing test the number of writhing was recorded during $30 \mathrm{~min}$ commencing $5 \mathrm{~min}$ after the intraperitoneal injection. A writhe is indicated by abdominal constriction and stretching of at least one hind limb according to the method described by Siegmund et al. [6]. Results were compared to the control animals (PBQ $0.4 \mathrm{~g} / \mathrm{Kg} \mathrm{w}$ ).

\section{Statistical analysis}

Data are presented as the mean \pm standard error (s.e.m). Statistical analysis was performed using Student's $t$-test. The significance of difference was considered to include values of $P<0.05$.

\section{Results}

It is of note that our results clearly showed that the selected effluents (TW, OMW and PW) and their 
biodegradation derivatives administrated alone to animals did not have any toxic effect (mortality, body weight, feed intake).

Results showed that no convulsion effects were shown by the tested TW and OMW (Table 1). The time taken before the onset of colonic convulsions and mortality were $0 \%$ respectively which was compared to the negative control (distillated water). However, PW wastewater exhibited a high power to induce a convulsant behaviour which observed in mice; in fact the time taken before the onset of colonic convulsions and mortality was $17 \pm$ 1.3 which was comparable to the positive control PTZ $90 \mathrm{mg} / \mathrm{kg}$ bw $(15 \pm 1.16)$. Onset of seizure observed in mice treated by PW $(230.5 \pm 13.5)$ exceeds that of PTZ (180.16 \pm 33.66).

Table 2 showed that all tested effluent (TW, OMW and PW) showed a significant effect to induce writhes. However, PW induced writhing more than TW and OMW, in fact, the number of writhing was recorded during $30 \mathrm{~min}$ were $44 \pm 2 ; 23 \pm 5$ and $26 \pm 3$, respectively. Pharmaceutical wastewater was more toxic than PBQ (reference compound). Writhing effect was completely disappears in mice treated by the tested effluent treated and the number of writhes which are comparable to those observed in mice treated by distillated water (Table 2).

\section{Discussion}

A common practice in Tunisia is to discharge untreated industrial effluents directly into neighbouring water bodies or onto agricultural land. As a result the quality of some local streams and rivers has been degraded to the point where the water is not safe for human or livestock use or for irrigation. Textile, olive oil mill and pharmaceutical wastewaters (TW, OMW and PW) are

Table 1 convulsant effect of the intraperitoneal administration of untreated and treated industrial TW, OMW and PW in comparison with the pentylenetetrazole (PTZ) $(90 \mathrm{mg} / \mathrm{ml})$ in mice

\begin{tabular}{cccc}
\hline Treatment & Onset of seizure & Duration (s) & Mortality (\%) \\
\hline PC & $180.16 \pm 33.66^{* *}$ & $15 \pm 1.16^{*}$ & 100 \\
\hline NG & 0 & 0 & 0 \\
\hline Untreated TW & 0 & 0 & 0 \\
\hline Untreated OMW & 0 & 0 & 0 \\
\hline Untreated PW & $230.5 \pm 13.5^{* *}$ & $17 \pm 1.3^{*}$ & 0 \\
\hline treated TW & 0 & 0 & 0 \\
\hline treated OMW & 0 & 0 & 0 \\
\hline treated PW & 0 & 0 & 0
\end{tabular}

Positive control: pentylenetetrazole (PTZ) $(90 \mathrm{mg} / \mathrm{ml}) ;$ Negative control: saline $10 \mathrm{ml} / \mathrm{kg}$

TW: Textile wastewater; OMW: olive Mill wastewater and PW: pharmaceutical wastewater

Values are expressed as mean \pm s.e.m. ${ }^{*} P<0.01 ;{ }^{*} P<0.001 \mathrm{n}=6$ animals
Table 2 Number of writhes in mice treated with each industrial wastewater before and after remediation with P.putida mt-2

\begin{tabular}{cc}
\hline Tested compound & $\begin{array}{c}\text { Number of writhes } \\
\mathbf{\pm} \text { s.e.m. }\end{array}$ \\
\hline NC & $00 \pm 00$ \\
\hline PC & $39 \pm 2^{* *}$ \\
\hline Untreated TW & $23 \pm 5^{*}$ \\
\hline Untreated OMW & $26 \pm 3^{*}$ \\
\hline Untreated PW & $44 \pm 2^{* *}$ \\
\hline Treated TW & $00 \pm 00$ \\
\hline Treated OMW & $3 \pm 1$ \\
\hline Treated PW & $00 \pm 00$
\end{tabular}

Positive control: phenobenzoquinone (PBQ); Negative control: distillated water TW: Textile wastewater; OMW: olive Mill wastewater and PW: pharmaceutical wastewater

Values are expressed as mean \pm s.e.m. ${ }^{*} P<0.01 ;{ }^{* *} P<0.001 \mathrm{n}=6$ animals

an environmental pollutants extremely toxics to plants and other living organisms including humans. In previous work [3-5]Pseudomonas putida mt-2 was revealed able to treat these effluents. However, we cannot accurately locate the toxicity of effluents and a key question arises is that such treatment leads to detoxification. The level of toxicity in the DNA, previously described [3-5], may not be sufficient and does not reflect the toxicity of the other part of the body among other things the brain. In this work, a single dose of intraperitoneal administration of pharmaceutical wastewaters caused strongly clonic convulsions (230.5 onset of seizure) which are higher than the reference drug PTZ (180.16 onset of seizure). Despite the difference in chemical structure between PTZ and drugs of PW contents, the latter has a higher convulsion effect. This could be explaining by several hypotheses. In fact, synergic effects between some or all drug of PW contents are responsible for the convulsion effects, or, metabolites deriving from UV or VIS degradation of these drug when released into the environment could show a similar chemical structure than PTZ, and consequently are responsible for the observed convulsion effect. Then, PW could induce epilepsy; this later is one of the most common serious neurological conditions. According to Aalbers et al. [7] and Luisa [8] the forbrain is involved in the expression of clonic seizures, whereas the activation of brainstem structures participates in the expression of the tonic component. Convulsive seizures could be attributed to the presence of drugs in PW which blocked $\gamma$-aminobutyric acid (GABA) receptor $\mathrm{Cl}^{-}$channels $[7,8]$. However, the two other effluents, TW and OMW, do show any convulsing effect. Seizures have traditionally been recognized as a symptom of abnormal neuronal synchronization, and until recently have been thought to be a result 
of aberrant synaptic communication $[9,10]$. This idea was confirmed by other models such as visceral pain. Among the several models of visceral pain, writhing test has been mostly used as a standard screening method [11]. All tested wastewaters are reveled able to induce algogenic effects. In fact intraperitoneal administration of the three industrial wastewaters produces significant abdominal contractions throughout the entire period of observation. Similarly, the PW has been proven to be very active and strongly induces pain that result in a remarkable number of cramps $(44 \pm 2)$, well above the $\mathrm{PBQ}$ (drug reference) $(39 \pm 2)$. TW and OMW also induce effects algogenic but lesser degree. The algogenic effect could be attributed especially to the presence of pharmaceutical drug, dyes and phenolic compounds in the PW, TW and OMW, respectively.

The induction mechanism of algogenic effects by these products could be defined according to two hypotheses. Molecules contained in effluents acts indirectly by inducing the release of endogenous mediator, which stimulates the nociceptive neurons sensitive to NSAIDs (nonsteroidal anti-inflammatory drugs) and/or opioids [12] but these molecules-induced writhing response could believed to be produced by the liberation of endogenous substance(s), notably metabolites of the arachidonic cascade $[12,13]$.

According to the toxic effects observed in these effluents, the search of a treatment is imperative. However, removal of numerous classes of pharmaceuticals, textile and olive mill from the industrial wastewater, using conventional wastewater treatment, is incomplete. In this work we suggested that improvement of this situation would require the application P. putida to the treatment of these effluents. This is particularly important for the treatment of industrial effluents, released from pharmaceutical, textile and olive mill industries, which can contain rather high concentrations of toxic compounds. In fact, any toxicity was observed when tested effluents treated by $P$. putida $\mathrm{mt}-2$.

\section{Acknowledgements}

The authors acknowledge the "Ministry of Higher Education, Scientific Research and Technology, Tunisia".

\section{Author details}

'Laboratoire de biotechnologie et Valorisation de Bio Géo Ressources (LBVBGR) Institut Supérieur de Biotechnologie - ISBST BioTechPole Sidi Thabet Université Manouba, Ariana 2020, Tunisie. 'Laboratoire de Recherche des Substances Biologiquement Compatibles, Faculté de Médecine Dentaire, Rue Avicenne, Monastir 5000, Tunisie.

\section{Authors' contributions}

HBM: Was responsible for the conception and design, testing and data acquisition, analysis and data interpretation and drafted the manuscript. AD: made contribution to the study algogenic activities. YA: made contribution to convulsing activity. All authors read and approved the final manuscript.

\section{Competing interests}

The authors declare that they have no competing interests.

Received: 15 January 2012 Accepted: 7 February 2012

Published: 7 February 2012

\section{References}

1. Gogate PR, Pandit AB: A review of imperative technologies for waste water treatment. I. Oxidation technologies at ambient conditions. Adv Environ Res 2004, 8:501.

2. Gogate $P R$, Pandit $A B: A$ review of imperative technologies for waste water treatment. II. Hybrid methods. Adv Environ Res 2004, 8:553.

3. Ben Mansour H, Mosrati R, Ghedira K, Chekir L: Decolorization of textiles finishing wastewater byPseudomonas putid: Toxicity assessment. Env Eng Sci 2011, doi:10.1089/ees.2010.0225.

4. Ben Mansour H, Mechri B, Ayed-Ajmi Y, Ghedira K, Barillier D, Hammami M, Mosrati R, Chekir L: Treatment of Olive Mill Wastewaters by Pseudomonas putida mt-2: Toxicity assessment of the untreated and treated effluent. Env Eng Sci 2011.

5. Ben Mansour H, Mosrati R, Barillier D, Ghedira K, Chekir L: Bioremediation of industrial pharmaceutical wastewater. Accepted for publication in Drug Chem Toxicol 2011

6. Siegmund EA, Cadmus RA, Lu G: A method for evaluating both nonnarcotic and narcotic analgesics. Proc Soc Exp Biol 1957, 95:729-731.

7. Aalbers M, Vles J, Klinkenberg S, Hoogland G, Majoie M, Rijkers K: Animal models for vagus nerve stimulation in epilepsy. Exp Neurol 2011, 230:167-175

8. Luisa R: Subchronic treatment with antiepileptic drugs modifies pentylenetetrazol-induced seizures in mice: its correlation with benzodiazepine receptor binding. Neuropsy Dis Treat 2008, 4:619-625.

9. Mohammad A, Hoornaz K, Hamid RME: Antinociceptive effects of Teucrium polium L. total extract and essential oil in mouse writhing test. Pharmacol Res 2003, 48:31-35.

10. Dayer JM, Schorderet M: Physiopathologie de la fièvre, de la douleur et de l'inflammation Dans: pharmacologie, des concepts fondamentaux aux applications thérapeutiques Genève: Frison-Roche, Paris \& Slatkine; 1998, 569-581.

11. Gené RM, Segura L, Adzet T, Marin E, Inglesias J: Heterotheca inuloides: anti-inflammatory and analgesic effects. J Ethnopharmacol 1998, 60:157-162.

12. Collier HOJ, Dineen LC, Johnson CA, Schneider C: Abdominal constriction response and its suppression by analgesic drugs in the mouse. $B \mathrm{~J}$ Pharmacol Chemother 1968, 32:295-310.

13. Formukong EA, Evans AT, Evans FJ: Analgesic and anti-inflammatory activity of constituents of Cannabis Sativ L. Inflammation 1988, 12:361-371.

doi:10.1186/1475-2867-12-4

Cite this article as: Mansour et al: Toxicities effects of pharmaceutical, olive mill and textile wastewaters before and after degradation by Pseudomonas putida mt-2. Cancer Cell International 2012 12:4.

\section{Submit your next manuscript to BioMed Central and take full advantage of:}

- Convenient online submission

- Thorough peer review

- No space constraints or color figure charges

- Immediate publication on acceptance

- Inclusion in PubMed, CAS, Scopus and Google Scholar

- Research which is freely available for redistribution

Submit your manuscript at www.biomedcentral.com/submit 